九州大学学術情報リポジトリ

Kyushu University Institutional Repository

\title{
Hygrothermal Behaviours of Wood Column Exposed to Outdoor Weather During One Month
}

\section{LEE, Yong Hun}

Department of Mathematics, and Institute of Pure and Applied Mathematics, Chonbuk National University

KANG, Chun Won

Department of Housing Environmental Design, and Research Institute of Human Ecology, College of Human Ecology, Chonbuk National University

MATSUMURA, Jun j $\mathrm{i}$

Laboratory of Wood Science, Division of Sustainable Bioresources Science, Faculty of Agriculture, Kyushu University

https://doi.org/10.5109/2232295

出版情報: 九州大学大学院農学研究院紀要. 64 (1)，pp.119-125，2019-02-28. Faculty of Agriculture, Kyushu University

バージョン :

権利関係 : 


\title{
Hygrothermal Behaviours of Wood Column Exposed to Outdoor Weather During One Month
}

\author{
Yong Hun LEE ${ }^{1}$, Chun Won KANG ${ }^{2}$ and Junji MATSUMURA \\ Laboratory of Wood Science, Division of Sustainable Bioresources Science, \\ Faculty of Agriculture, Kyushu University, Fukuoka 819-0395, Japan \\ (Received October 31, 2018 and accepted November 12, 2018)
}

\begin{abstract}
This article presents the numerical simulation results. The governing equation was developed using assumption on the moisture driving potentials and the phenomenological coefficients. The simulation results by control volume finite element method were compared to experimentally estimated results. The effect of moisture transfer rate on the heat diffusion was not significant because the heat diffusion was much faster than the moisture diffusion. The average temperature and its distribution under external dynamic conditions calculated using apparent heat diffusion coefficient were similar from the engineering point of view.
\end{abstract}

Key words: Nonisothermal transport model, desorption and adsorption, drying, building physics, phenomenological transport coefficients, sorption isotherm

\author{
Notation \\ $\Delta h_{v}$ : latent heat of evaporation $(\mathrm{J} / \mathrm{kg})$ \\ $M_{v}$ : molecular weight of water vapour $(\mathrm{kg} / \mathrm{mol})$ \\ $P_{v}$ : partial vapour pressure $(\mathrm{Pa})$ \\ $P_{v s}:$ saturated vapour pressure $(\mathrm{Pa})$ \\ $P_{v s, \infty}:$ saturated vapour pressure of surrounding air $(\mathrm{Pa})$ \\ $R$ : universal gas constant $(8.314 \mathrm{~J} / \mathrm{mol} \mathrm{K})$ \\ $\rho:$ wood density $\left(\mathrm{kg} / \mathrm{m}^{3}\right)$ \\ $\rho_{\text {ow }}:$ density of oven-dried wood $\left(\mathrm{kg} / \mathrm{m}^{3}\right)$ \\ $\rho_{a}:$ air density $\left(\mathrm{kg} / \mathrm{m}^{3}\right)$ \\ $\rho_{v}$ : water vapour density at the wood surface $\left(\mathrm{kg} / \mathrm{m}^{3}\right)$ \\ $\rho_{v, \infty}$ : water vapour density of surrounding air $\left(\mathrm{kg} / \mathrm{m}^{3}\right)$ \\ $a_{i j}$ : transfer coefficients $(i, j=1,2)$ \\ $C_{p}$ : specific heat of wood $(\mathrm{J} / \mathrm{kg} \mathrm{K})$ \\ $C_{p a}$ : specific heat of air $(\mathrm{J} / \mathrm{kg} \mathrm{K})$ \\ $C_{p v}:$ specific heat of water vapour $(\mathrm{J} / \mathrm{kg} \mathrm{K})$ \\ $G$ : incident solar radiance $\left(\mathrm{W} / \mathrm{m}^{2}\right)$ \\ $m$ : fractional moisture content (dimensionless)
}

\author{
$T:$ temperature $(\mathrm{K})$ \\ $T_{\infty}$ : temperature of surrounding air $(\mathrm{K})$ \\ $T_{s}$ : temperature at wood surface $(\mathrm{K})$ \\ $T_{\text {sky }}:$ temperature of sky $(\mathrm{K})$ \\ $\alpha$ : solar absorptivity $(-)$ \\ $\varepsilon$ : solar emissivity $(-)$ \\ $\kappa$ : wind-driven coefficient $(\mathrm{s} / \mathrm{m})$ \\ $h_{c}$ : external convective mass transfer coefficient $(\mathrm{m} / \mathrm{s})$ \\ $h_{m}$ : external convective mass transfer coefficient $\left(\mathrm{kg} / \mathrm{m}^{2} \mathrm{~s}\right)$ \\ $h_{T}$ : external convective heat transfer coefficient $\left(\mathrm{W} / \mathrm{m}^{2} \mathrm{~K}\right)$ \\ $I_{h}$ : total radiation on a horizontal surface $\left(\mathrm{kJ} / \mathrm{m}^{2}\right)$ \\ $I_{b, h}$ : beam radiation on a horizontal surface $\left(\mathrm{kJ} / \mathrm{m}^{2}\right)$ \\ $I_{d, h}$ : diffuse radiation on a horizontal surface $\left(\mathrm{kJ} / \mathrm{m}^{2}\right)$ \\ $I_{o, h}$ : extraterrestrial radiation on a horizontal surface $\left(\mathrm{kJ} / \mathrm{m}^{2}\right)$ \\ $k_{t}:$ clearness index \\ $T_{a}:$ ambient temperature(C) \\ $h$ : relative humidity (dimensionless)
}

\section{INTRODUCTION}

Wood exposed to outdoor weather is susceptible to the environmental degradation such as weathering and decay. Weathering is due to a complex combination of chemical, mechanical, and light energy factors while decay results from decay fungi acting in the presence of the suitable temperature, moisture and air for an extended period of time.

Therefore, the degradation is closely related to the hygrothermal history. Understanding the hygrothermal behaviours of exposed wood components such as a column is interesting to predict the performances and life cycle assessment.

${ }^{1}$ Department of Mathematics, and Institute of Pure and Applied Mathematics, Chonbuk National University, Jeonju 561-756, Republic of Korea

${ }^{2}$ Department of Housing Environmental Design, and Research Institute of Human Ecology, College of Human Ecology, Chonbuk National University, Jeonju 54896, Korea

* Corresponding author: (E-mail: kcwon@jbnu.ac.kr) (ChunWon KANG)
Most researches on the moisture content changes in wood were conducted in timber drying field. There can be found numerous publications on heat and mass transfer models during drying. However, much less attention is paid on investigations of moisture content changes in timber as building components going through the cyclic process of desorption as well as adsorption or absorption. This might be mainly due to the uncertainty of material properties for the simulation. The moisture content changes of wooden plates placed in an instrument shelter were measured for one week (Sadoh and Yamazoe, 1993). The seasonal changes in moisture content of wood were measured for half a year and compared with the simulation results (Yamazoe and Sadoh, 1993). The results of the numerical modelling were compared to the experimental results of the moisture content changes of timber stored in an open shed during one year (Gugenda et al., 2005). However, these three researches were focused on the moisture change of wood below fiber saturation point and the specimens were placed in an open shed during the experiments. Fick's equations with a surface emission layer was applied for the simulation, which resulted in consistency 
with the measured values. There are few researches available for the behavior of wood that is directly exposed to the outdoor and did not get caught in rain.

It is generally thought that external convective transfer coefficients are only functions of external conditions, not of the material properties in the specimen. This cause an uncertainty in the determination of all mass transfer coefficients (Wadso, 1993). Moisture damage is one of the most important factors limiting building's service life. In the field of building physics, therefore, numerous researches on hygrothermal performance of building materials and components have been done actively (Trechsel, 1994). Because building facades are often exposed to the rain, the rain is the most important moisture source affecting the hygrothermal performance and durability of building facades. The rain, more precisely wind-driven rain(WDR), among moisture sources is most dominant and several hundred times larger than the moisture content in the surrounding air for wood or its components. In recent, Blocken and Carmeliet (2004) reviewed the state-of-the-art of WDR research in building science. The limited amounts of data are available for WDR phenomena that are not fully understood.

The heat and mass transfer models are basically similar although there are some different in adapting state variables as driving forces, cross transport coefficients (Soret effect and its reciprocal Dufour effect) and assuming air pressure in wood. However, there are still difficulties in predicting the hygrothermal performance and defining the problem well for the following reason. Boundary conditions are difficult to define, especially in case of wood exposed to rain. In addition, material properties are highly variable among species and even within a tree and not showing a consistency for different specimens. Furthermore, it is difficult to measure diffusion coefficient, sorption isotherm, water retention curve, their hysteresis and so on. And the last, the governing equations are highly nonlinear and it is difficult to handle. Because the efficiency depends on the equations adapted and nonlinearity, there is no unique numerical method that is most suitable for solving the equations.

The variation of the ambient air parameters is characterized by daily and yearly periodicities which are randomly disturbed by weather changes. Except the air parameters the mean moisture content is also influenced by timber dimensions, primary by thickness. When timber is stored in an open shed its moisture content changes due to the natural variation of the air parameters. The wide range of the potential changes of timber moisture content depending on the climate conditions as well as on the exposure. The similar relations can be expected for long-lasting storage of dry timber in open sheds. However, there is a lack of the relations for dry timber which could predict moisture content changes for variable parameters of the ambient air.

Moisture in wood exists in three phases of water vapor, bound water, and free water above fiber saturation point (FSP). There are two phases of water vapor in the cell cavities and bound water in the cell walls below the FSP that is in the hygroscopic range. The maximum bound water content is called to the FSP that is limited by the number of sorption site available. It may be different among species because their chemical compositions vary but is usually assumed that the FSP is $30 \%$ water based on dry wood weight at the room temperature.

It is well documented that the driving potential for the movement of free water and water vapor is a gradient of capillary pressure and vapor pressure, respectively. Furthermore, the flux of water vapor can be divided into the convection component of the gas mixture flux and the diffusion component of water vapor under the effect of a gradient in vapor concentration. The driving potential for the bound water is different by researchers and can be expressed in terms of a number of different system variables. In the literature we can find the formulations of nonisothermal transport models that are widely accepted in wood drying and other research fields. Perre's model (1993) is based on the multiphase transfer model by Whitaker (1977) but he involved an additional potential of bound water to it. He focused on the heat and mass transfer modelling above boiling point of water in which the mass transfer by water vapor convection gas is dominant. The bound water diffusion coefficient is based on the Stamm's results in which it is similar to the Avramidis model (1992). Kamke and Vanek (1994) compared the capacities of 12 wood drying models with experimental drying results of moisture change rate and its distribution. They stated that there was a high variability between models' results that were not in close agreement with the test runs although none of the models violated any of the known wood drying phenomena. It might be due to the uncertainty of coefficients for the models, different degrees of simplifications, and different ways of solving the heat and mass transfer equations. In addition, the equations to boundary conditions and external heat and mass convection coefficients are usually different among models, which might cause a great effect on the numerical results.

The objective of the present study is to investigate the hygrothermal performances of wood column fully exposed to outdoor weather conditions including air temperature, relative humidity, solar radiation, rain, and wind speed. It is to survey the feasibility of heat and mass transfer model adapting Darcy's law, Fick's law and Fourier's law. Using the material properties known previously, finally, it is to validate the modeling by the comparison of the results of the prediction to experimentally determined temperature and moisture content of wood column.

\section{MATERIALS AND METHODS}

\section{Materials}

A sample column of Douglas-fir was used in this numerical simulation, which were air-dried in the indoor environment for more than a half-year and to about $12 \%$ moisture content. The wood columns with dimension of $2.4 \mathrm{~m} \times 0.2 \mathrm{~m} \times 0.2 \mathrm{~min}$ were cut into three in length of 
$0.7 \mathrm{~m}$. The average density of wood columns was $437 \mathrm{~kg} /$ $\mathrm{m}^{3}$, ranged from $424 \mathrm{~kg} / \mathrm{m}^{3}$ to $455 \mathrm{~kg} / \mathrm{m}^{3}$.

The top and bottom of wood column were insulated by aluminum foil and Styrofoam. For measuring thermal and moisture content changes, the columns were exposed to outdoor weather conditions for one month, from 1 May 2007 to 31 May 2007. The column was placed in four cardinal directions. The field test was conducted at Chonnam National University, located at Gwangju in Korea. $\mathrm{K}$ type of thermocouples was used for measuring the temperatures of surface and inside of the wood column in depth of $30 \mathrm{~mm}, 50 \mathrm{~mm}, 80 \mathrm{~mm}$ and $100 \mathrm{~mm}$. Temperatures were set to be data-logged automatically at one minute interval.

To estimate the surface or highest moisture content, the electrical resistance was measured by using the portable insulation tester called mega-ohmmeter in the market. For doing this, nails were inserted at the same depth of thermocouples installed. The distance between two nails was $2.5 \mathrm{~cm}$. Electric resistance was measured three times per day $(5: 30,13: 30,18: 30)$. The electrical resistance measured was converted to moisture content by the following empirical equation (Skaar, 1988).

$$
M_{e}=\frac{1.009-\log [\log (R)-4]}{0.0322}
$$

where $M_{e}$ is moisture content (\%), $R$ electric resistance $(\Omega)$, T temperature $\left({ }^{\circ} \mathrm{C}\right)$.

It should be noted that equation (1) based on data obtained from European Oak at $20^{\circ} \mathrm{C}$ and holds on between $3 \%$ to $23 \%$ wood moisture content. Correction of moisture content for temperature was approximated by

$$
\frac{d M}{d T}=0.027+0.0085 M
$$

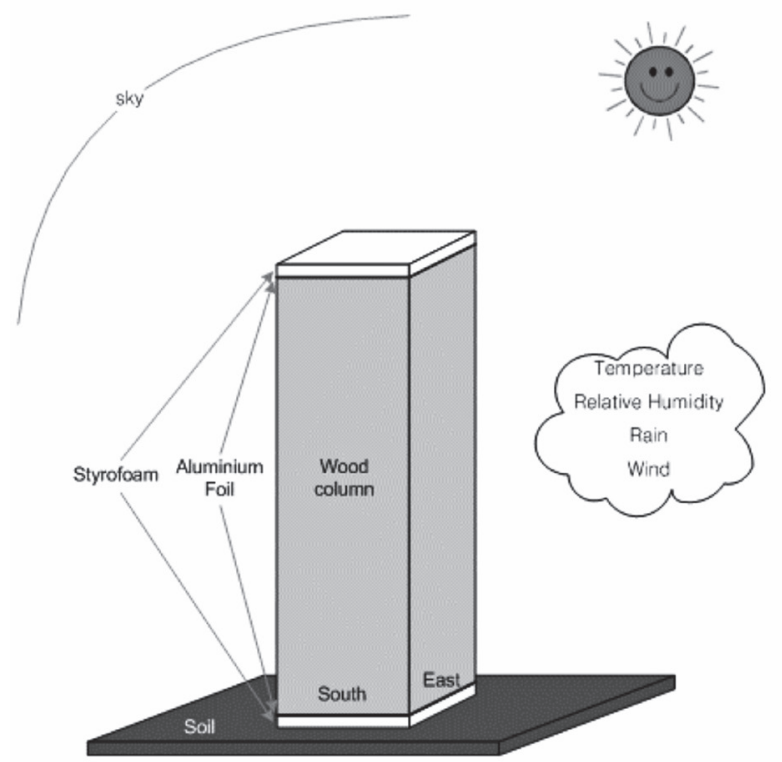

Fig. 1. Schematic view of wood column in outdoor environment.
Therefore,

$M=\frac{M_{e}-0.027(T-20)}{1+0.0085(T-20)}$

(Skaar C. 1988. Wood-water relations. p210. Springer-Verlag)

Formulation of the heat and mass transfer equations

The coupled heat and mass transfer equations with two state variables of moisture content $(m)$ and temperature (T) can be represented (Kang et al, 2008).

$$
\begin{aligned}
& \rho_{o w}=\frac{\partial m}{\partial t}=\nabla \cdot\left(a_{11} \nabla m\right)+\nabla \cdot\left(a_{12} \nabla T\right) \\
& \rho C_{p}=\frac{\partial T}{\partial t}=\nabla \cdot\left(a_{21} \nabla m\right)+\nabla \cdot\left(a_{22} \nabla T\right)
\end{aligned}
$$

Where, the density and specific heat with moisture content are represented by Forest Products Laboratory (1999).

$$
\begin{aligned}
\rho= & \frac{\rho_{0 w}(1+m)}{\left(1+m \rho_{0 u} / 1000\right)} \\
C_{p}= & \frac{103.1+3.867 T+4190 m}{1+m} \\
& +m(-6191+23.6 T-1330 m)
\end{aligned}
$$

If wood is exposed to rain, the surface moisture content will be increased above FSP. However, the amount of water that can be penetrated into wood is limited by maximum moisture content that depends on the wood density. It will be in capillary moisture content that is lower than maximum MC. It depends on the material geometry, topology around wood, wind speed, wind direction, rain intensity, and rain droplet distribution (Blocken and Carmeliet 2004).

The boundary conditions at exposed surfaces are given by:

$$
\begin{aligned}
& -a_{11} \nabla m-a_{12} \nabla T=h_{c}\left(\rho_{\infty, v}-\rho_{v}\right)+R_{w d r} \\
& -a_{21} \nabla m-a_{22} \nabla T=h_{T}\left(T_{s}-T_{\infty}\right)+h_{c} \Delta h_{v}\left(\rho_{v}-\rho_{\infty, v}\right) \\
& -q_{r, \text { net }}+R_{w d r} T_{\infty} C_{p, l}
\end{aligned}
$$

The vertical rain intensity or wind driven rain, $R_{w d r}(\mathrm{~mm} / \mathrm{h})$, acting on the column surface is assumed to be related to the wind speed and horizontal rain intensity(van Mook, 2002).

$$
R_{w d r}=\kappa U R_{h}^{\beta} \cong 0.222 U R_{h}
$$

Where, $R_{h}(\mathrm{~mm} / \mathrm{h})$ is the horizontal rain intensity in the undisturbed wind flow. $\kappa$ and $\beta$ are empirical constants. $\kappa$ has close relation with the inverse of the rain terminal velocity of fall. $U(\mathrm{~m} / \mathrm{s})$ is the wind speed. Equation (10) is realistic for spells of light to moderate intensity.

The net solar radiance can be expressed by the following equation (Duffie and Beckman, 1991).

$$
q_{r, \text { net }}=\alpha G-\varepsilon \sigma\left(T_{s}^{4}-T_{s k y}^{4}\right)
$$

The equations (8) and (9) can be rewritten using the expression of the density of water vapour to mois- 
ture content.

$$
\begin{aligned}
& -a_{11} \nabla m-a_{12} \nabla T=h_{m}\left(m_{\infty}-m\right)+0.222 U R_{h} \\
& -a_{21} \nabla m-a_{22} \nabla T=h_{T}\left(T_{\infty}-T\right)+h_{m} \Delta h_{v}\left(m_{\infty}-m\right) \\
& -q_{r, n e t}+0.222 U R_{h} T_{\infty} C_{p, l}
\end{aligned}
$$

Where, $h_{m}$ and $h_{T}$ are the external convective mass and heat transfer coefficients, respectively.

$$
h_{m}=h_{c} \frac{M_{v} p_{v s, \infty}}{R T} \frac{\partial h}{\partial m}
$$

The two convective transfer coefficients are dependent each other if the Prandtl and Schmidit numbers, or the thermal and water vapour diffusivities are equal. If the Nusselt and Sherwood numbers would be equal and the Lewis number equals to unity, leading to the Lewis relation.

$$
h_{c} \cong \frac{h_{T}}{\rho_{a} C_{p a}}
$$

Therefore, a convective mass transfer coefficient can be evaluated from convective heat transfer coefficients that are more established from the literature data. However, it may require a correction factor to reduce the $h_{m}$ value because the Lewis analogy can be used if the surface is moist as an open liquid surface (Tremblay, 2000). The mass (moisture) content in porous material is usually expressed as moisture concentration $\left(\mathrm{kg} / \mathrm{m}^{3}\right)$, volumetric content $\left(\mathrm{m}^{3} / \mathrm{m}^{3}\right)$ and fractional moisture content $(\mathrm{kg} / \mathrm{kg})$. The percentage moisture content used in this study is based on fractional moisture content.

The boundary conditions at symmetric surfaces are given by:

$$
\begin{aligned}
& -a_{11} \nabla m-a_{12} \nabla T=0 \\
& -a_{21} \nabla m-a_{22} \nabla T=0
\end{aligned}
$$

To predict the radiation on a vertical or column surface, it should be known to be the direct, diffuse and reflected radiation. However, measurement data usually give the total radiation only on the horizontal surface. According to Reindl et al.(1990), The horizontal diffuse radiation depends on the ambient temperature and the relative humidity as well as the sky clearness, which can be estimated from the from the total radiation on the horizontal surface. Diffuse radiation consists of the radiation reflected from clouds and the scattered radiation.

$$
\begin{aligned}
0 \leq & k_{T} \leq 0.3 \\
I_{d, h}= & I_{h}\left(1.0-0.232 k_{T}+0.0239 \sin \alpha\right. \\
& \left.-0.000682 T_{a}+0.0195 h\right) \\
0.3 & \leq k_{T} \leq 0.78 \\
I_{d, h}= & I_{h}\left(1.329-1.716 k_{T}+0.267 \sin \alpha\right. \\
& \left.\quad-0.00357 T_{a}+0.106 h\right) \\
0.78 & \leq k_{T} \\
I_{d, h}= & I_{h}(0.426+0.256 \sin \alpha \\
& \left.-0.00349 T_{a}+0.0734 h\right)
\end{aligned}
$$

Where, $\alpha$ is solar altitude angle (see Figure 2). Once the diffuse fraction is known, the direct radiation is given by

$$
I_{b}=\frac{I_{h}-I_{d, h}}{\cos z}
$$

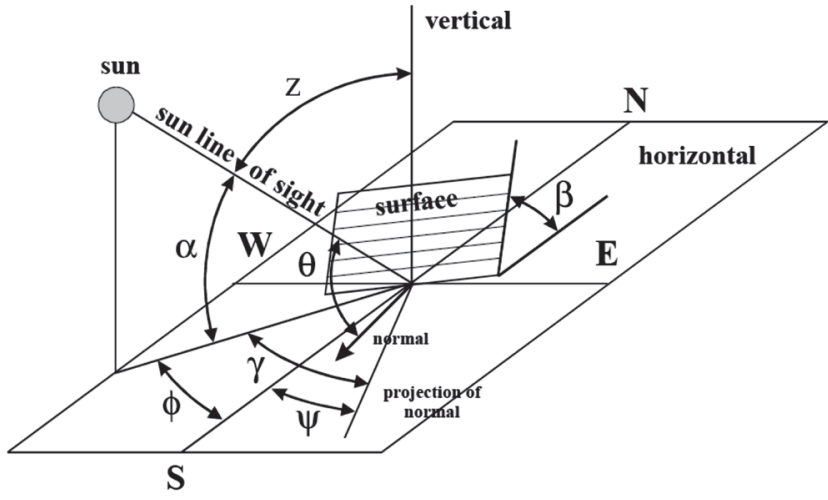

Fig. 2. Definitions of solar angles to calculate the solar geometry.

Where, $z$ is zenith angle (see Figure 2).

The clearness index is defined as the ratio of the extraterrestrial radiation to the total radiation on a horizontal surface.

The extraterrestrial radiation can be expressed as

$$
I_{0}=I_{s c}\left(1+0.033 \cos \frac{360 n}{365}\right)
$$

Where, $I_{s c}$ is the radiation emitted by the sun $\left(I_{s c}=\right.$ $1353 \mathrm{w} / \mathrm{m}^{2}$ ) and $n$ is the day of the year.

On a tilted surface,

$I_{t}=I_{b, t}+I_{d, t}+I_{r, t}$

The direct radiation is the projection of the direct radiation on the horizontal surface.

$$
I_{b, t}=I_{b} \cos \theta
$$

where $\theta$ is incidence angle (see Figure 2). The diffuse radiation can be calculated from

$$
\begin{aligned}
I_{d, t}= & \frac{1}{2} I_{d, h}(1+\cos \beta)\left(1-F_{H}\right)\left[1+F_{R} \sin \left(\frac{\beta}{2}\right)\right] \\
& +\frac{\cos \theta}{\cos z} F_{H} \\
F_{H}= & \frac{I_{b}}{I_{0}} \\
F_{R}= & \sqrt{1-\frac{I_{d, h}}{I_{h}}}
\end{aligned}
$$

where $\beta$ is tilt (or slope) angle (see Figure 2). The factor $F_{H}$, referred to as the anisotropy index, is a weighting factor between the isotropic model and the assumption that all energy originates from the sun. The factor $F_{R}$ controls the horizon brightening. The Reindl model gives the smallest mean bias error on the average yearly sum of diffuse irradiation on tilted surfaces. The reflected radiation consists of a ground-reflected part and reflections from the building environment. The ground reflected part is calculated as the sum of the direct and diffuse radiation falling on the ground multiplied by the ground reflectance $\rho_{\mathrm{g}}$ and the view factor from the ground to the surface.

$$
I_{r, t}=\left(I_{b}+I_{d, h}\right) \rho_{\mathrm{g}} \frac{1-\cos \beta}{2}
$$

For a vertical surface, the diffuse radiation is $50 \%$ of the horizontal diffuse radiation. Reflection from the sur- 
rounding buildings is not considered in this study.

\section{RESULTS AND DISCUSSION}

\section{Numerical analysis}

Some numerical simulations by the control volume finite element method were carried out for the twodimensional heat and mass transfer process for a wood sample. Details of the control volume finite element method can be found by Lee et al. (2007). It was assumed that all the surfaces were exposed to the same external conditions, and the quarter of the domain is considered in the numerical analysis by making of the symmetry.

The sample was exposed to the real external condition from $1^{\text {st }}$ May 2007 to $31^{\text {st }}$ May 2007, in Gwangju, S. Korea. In this numerical computation, as shown in fig $3-7$, we used relative humidity, air temperature, solar radiation, wind speed and rain fall data as climate parameter.

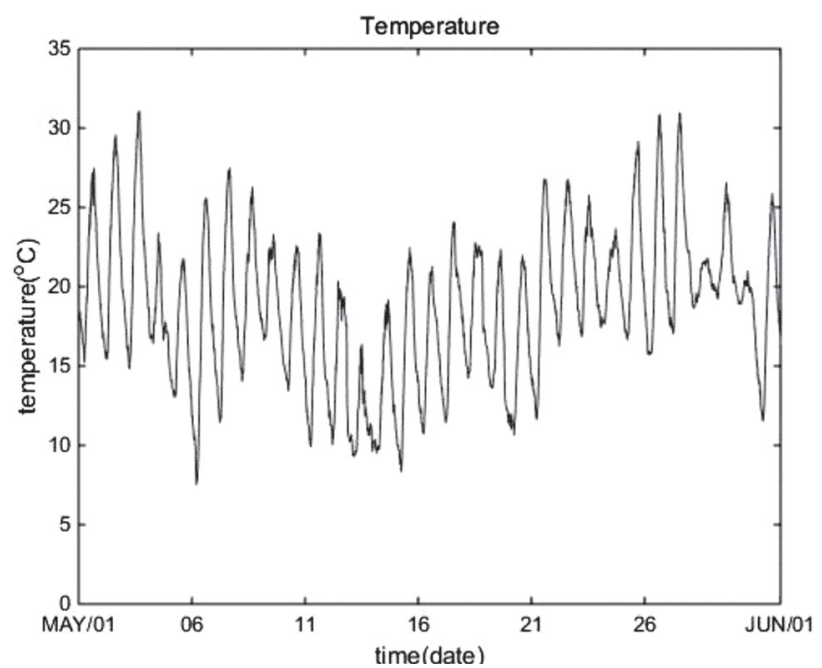

Fig. 3. The air temperature from 1 May 2007 to 31 May 2007, at Gwangju in S. Korea.

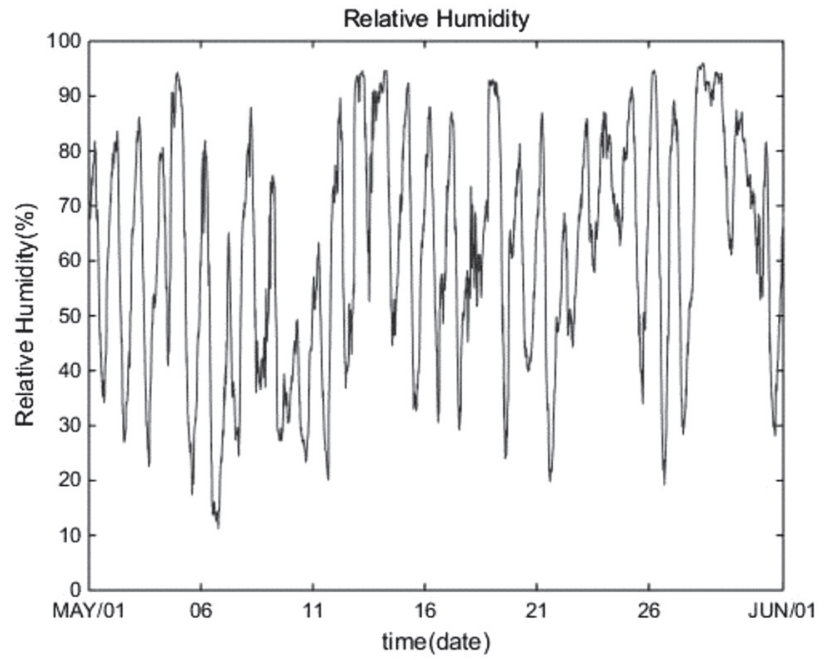

Fig. 4. The relative humidity from 1 May 2007 to 31 May 2007, at Gwangju in S. Korea.

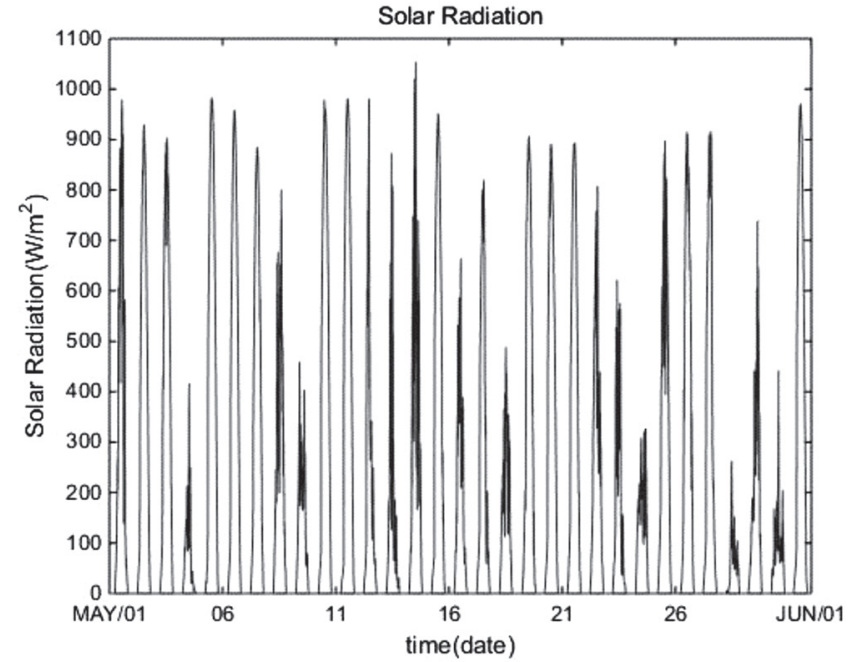

Fig. 5. The solar radiation energy from 1 May 2007 to 31 May 2007, at Gwangju in S. Korea.

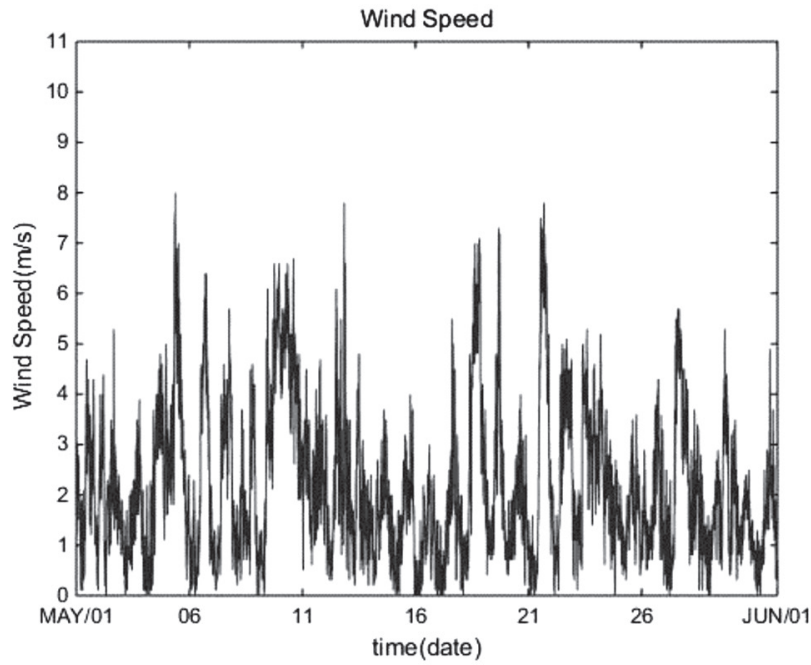

Fig. 6. The wind speed from 1 May 2007 to 31 May 2007, at Gwangju in S. Korea.

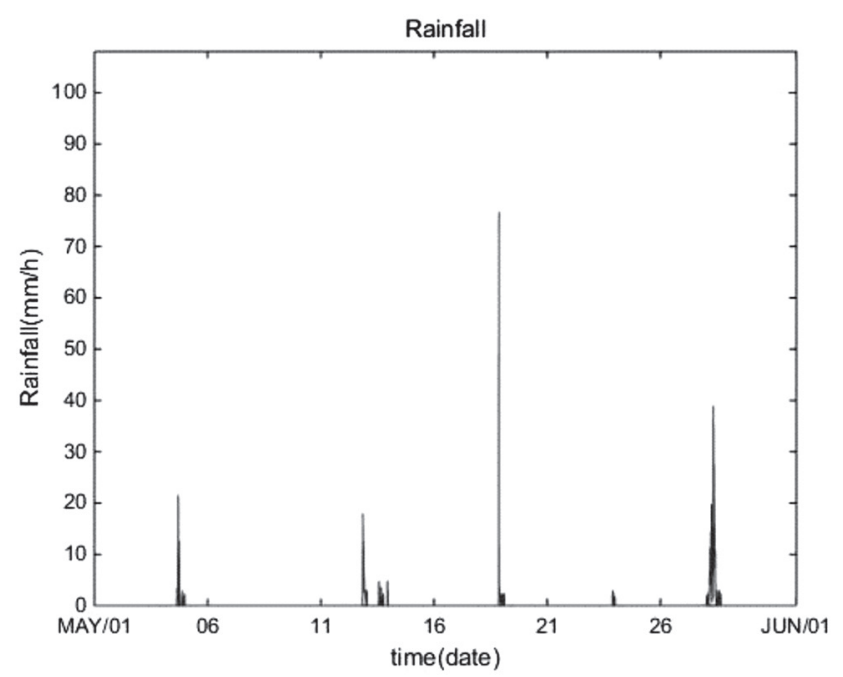

Fig. 7. The rainfall from 1 May 2007 to 31 May 2007, at Gwangju in S. Korea. 
The internal temperature of wood by experimentally estimated values is shown as figure 8. The figure shows that the internal temperature changed during from $1^{\text {st }}$ May 2007 to $31^{\text {st }}$ May 2007. The internal temperature was changed by external climate condition, mainly influenced by air temperature. The internal temperature fluctuated between 15-20 and 40-45 degrees, the fluctuation of internal temperature was about 20-25degrees. In rainy day, the fluctuation of internal temperature was decreased about 10degrees. As the evaluation layer became deeper, the internal temperature change was delayed.

The moisture content of wood experimentally estimated values is shown as figure 10. The figure shows that the moisture content evaluated at the center of the wood column changed during from $1^{\text {st }}$ May 2007 to $31^{\text {st }}$ May 2007. The moisture content was changed by external climate condition, mainly influenced by rainfall. The moisture content fluctuated between 10-13\% during 11 days. The moisture content reached to $20 \%$ by rainfall, and the fluctuation variance of moisture content was

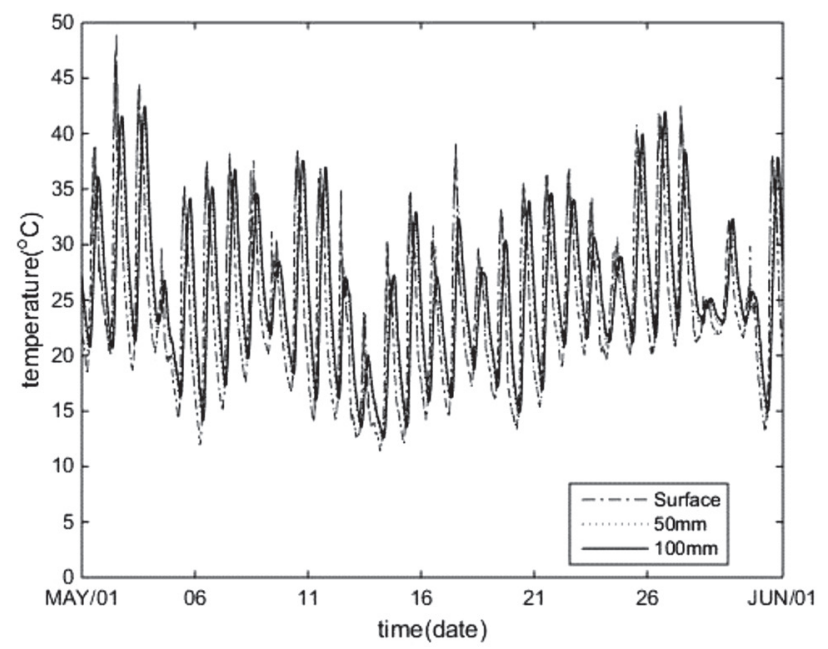

Fig. 8. The experimentally estimated internal temperature changes of wood column during one month.

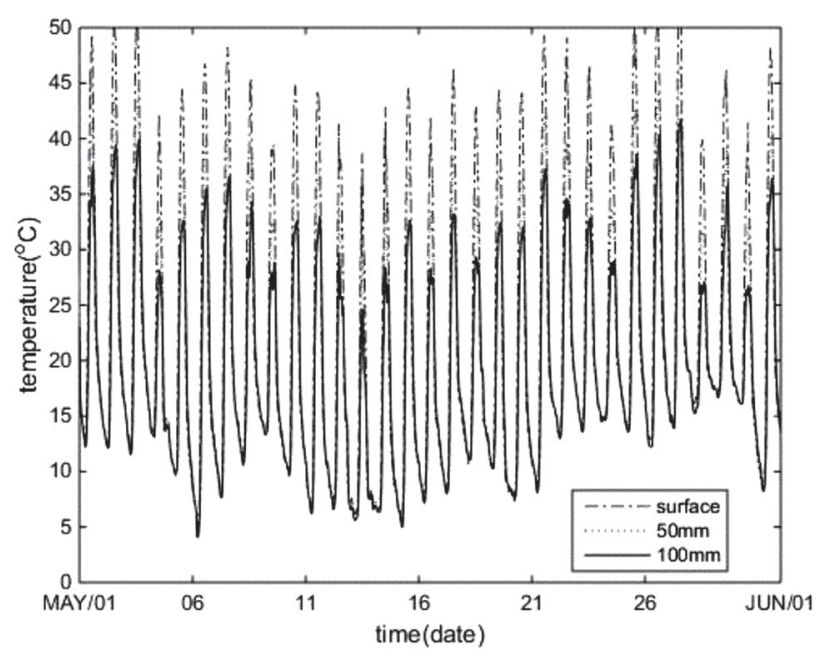

Fig. 9. The predicted internal temperature changes of wood column during one month. reached to about $10 \%$. The moisture content of central part of wood column was relatively low.

\section{Comparison between calculated and evaluated internal temperature and moisture content of out- door exposed wood column}

The predicted value of the internal temperature of wood is shown as figure 9. The figures show that the temperature at the surface of wood column reached $40-50^{\circ} \mathrm{C}$ while the value of central layer reached $25-30^{\circ} \mathrm{C}$. The predicted value of the internal temperature of wood was in reasonable agreement with the experimentally estimated values.

The predicted value of the moisture content of wood is shown as figure 11. The figure shows that the moisture content at the center layer of the wood column changed during from $1^{\text {st }}$ May 2007 to $31^{\text {st }}$ May 2007. The moisture content was changed by external climate condition, mainly influenced by rainfall. The moisture content fluctuated between 10-13\% during 4days. The moisture content was reached to $17 \%$ by rainfall, the

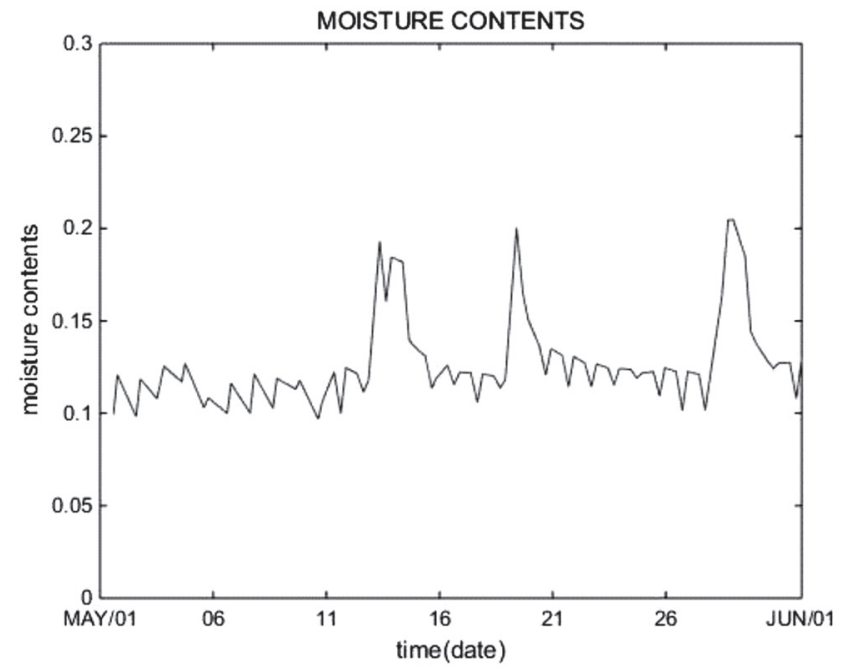

Fig. 10. The experimentally estimated moisture content changes of wood column during one month.

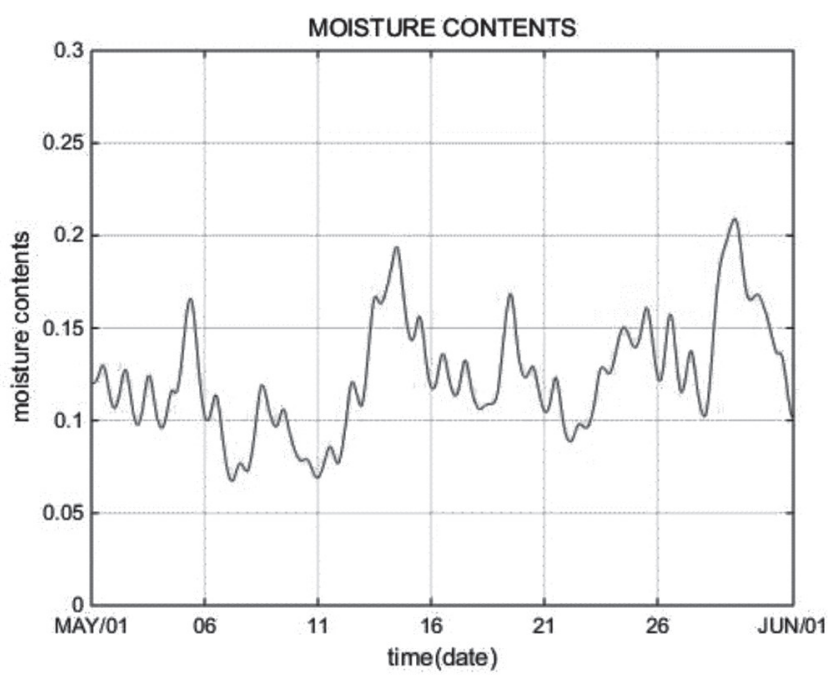

Fig. 11. The predicted moisture content changes of wood column during one month. 
fluctuation of moisture content was reached to about $10 \%$. The computed moisture contents of wood column showed very close values to those of measured data.

\section{CONCLUSIONS}

To evaluate the possibility for prediction of moisture content and temperature in wood exposed to outdoor, those values of Douglas-fir wood column estimated by mathematical simulation, we estimated the internal temperature of wood and moisture content experimentally and compared with those values estimated by mathematical simulation. The results are summarized as follows:

It is important to understand what assumptions have been made and applicability for the coupled heat and mass transfer models. The accuracy of heat and mass transport model depends on the governing equation, phenomenological coefficients, boundary conditions, and external heat and mass convection coefficients.

The computed internal temperature approximately agreed with the experimentally estimated one and the predicted moisture content was closely agreed with the experimentally estimated one. It is considered that the mathematical simulation can predict the moisture content and temperature in wood exposed to outdoor environment.

\section{ACKNOWLEDGMENTS}

This study was carried out with the support of Basic Research Project (Project No. NRF2017R1A2B4012538) provided by National Research Foundation of Korea), and "Research Base Construction Fund Support Program" funded by Chonbuk National University in 2018.

\section{REFERENCES}

Avramidis, S., P. Englezos and Papathanason 1992 Dynamic nonisothermal transport in hygroscopic porous media: moisture diffusion in wood. AIChE Journal. 38(8): 1279-1287

Blocken, B., J. Carmeliet 2004 A review of wind-driven rain research in building science. $J$ Wind Engineering and Industrial Aerodynamics. 92: 1079-1130

Guzenda, R., W. Olek and M. Gołębiewska 2005 Modelling moisture content changes in timber due to natural variation of ambient air parameters. Folia Forestalia Polonica. 36: 85-93

Kamke, F. A. and M. Vanek 1994 Comparison of wood drying models. 4th IUFRO International Wood Drying Conference, Rotorua, NZ.

W, Kang., Chung. WY., Eom. CD., and Yeo. HM 2008 Some considerations in heterogeneous nonisothermal transport models for wood: a numerical study. J Wood Science. 54: 267-277

YH, Lee., Kang. W and Chung. WY 2007 Numerical solution for wood drying on one-dimensional grid. $J$ Korean Society for Industrial and Applied Mathematics. 11(1): 95-105

Mounji, H., J. M. Vergnaud 1992 Condensation-sorption of water history with a cubic specimen of wood. Drying Technology. 10(5): 1287-1307

Perre, P., M. Moser and M. Martin 1993 Advances in transport phenomena during convective drying with superheated steam and moist air. Int J Heat Mass Transfer. 36: 2725-2746

Reindl, D. T., W. A. Beckman and J. A. Duffie 1990 Diffuse fraction correlations. Solar Energy. 45: 1-7

Reindl, D. T., W. A. Beckman and J. A. Duffie 1990 Evaluation of hourly tilted surface radiation models. Solar Energy. 45: 9-17

Sadoh,T., M. Yamazoe 1993 Predicting moisture content changes of wood exposed to daily temperature and humidity changes. Mokuzai Gakkaishi. 39(5): 555-560

Siau, J. F., S. Avramidis 1996 The surface emission coefficient of wood. Wood and Fiber Science 28(2): 178-185

Tremblay, C., A. Cloutier and Y. Fortin 2000 Experimental determination of the convective heat and mass transfer coefficients for wood drying. Wood Science and Technology. 34: 253-276

Van Mook F. 2002. Driving rain on building envelopes. Eindhoven University Press

Wadso L 1993 Surface mass transfer coefficients for wood. Drying Technology 11(6): 1227-1249

Yamazoe, M., T. Sadoh 1993 Predicting moisture content fluctuations of wood accompanying the weather and seasonal changes of atmosphere. Mokuzai Gakkaishi 39(7): 788-794 